\title{
El peso territorial de los movimientos LGBT. El caso de Bahía Blanca (Argentina)*
}

\section{The territorial weight of LGBT movements. The case of Bahía Blanca (Argentina)}

\author{
José Ignacio Larreche \\ Doctorando en Geografía. Becario doctoral del Consejo Nacional de Investigaciones Científicas y Técnicas (CONICET). Departamento \\ de Geografía y Turismo. Universidad Nacional del Sur (UNS-CONICET). 12 de octubre 1198, $4^{\circ}$ piso, (8000) Bahía Blanca, Buenos Aires, \\ Argentina, joseilarreche@gmail.com
}

Recibido: 26 de abril 2019 || Aprobado: 5 de marzo 2020

\section{Resumen}

Las movilizaciones sociosexuales tuvieron su puntapié en la segunda mitad del siglo XX, tomando como referencia las revueltas de Stonewall. Las amplificaciones suscitadas a posteriori tienen vigencia hasta el día de hoy, a pesar de que sus principales despliegues y abordajes analíticos han recaído en espacios metropolitanos. El presente esfuerzo quiere ver las particularidades que se suscitan en la otra cara de la moneda (los no metropolitanos) desde una perspectiva territorial. Se parte de considerar un enfoque cultural-emocional de los movimientos sociales partiendo de la observación participante efectuada durante la VII Marcha del Orgullo LGBT de Bahía Blanca en el año 2017. La fase territorial del evento permite reflexionar sobre el rol social del espacio público por donde transcurre, las dimensiones de la manifestación involucradas y las intersecciones imaginarias que adquiere el caso con su equivalente en la capital nacional, en un horizonte orientado a federalizar dichas vivencias.

Palabras clave: Geografía de las sexualidades; Movimientos socioterritoriales; Espacios no metropolitanos; Interescalaridad

Abstract

The socioexual mobilizations had their kick in the second half of the twentieth century, taking as reference the Stonewall riot. The amplifications raised as a consecuence are valid until today despite the fact that their main deployments and analytical approaches have fallen to metropolitan spaces. The present effort wants to see the particularities that arise on the other side of the coin from a territorial perspective. It starts from considering a cultural-emotional approach to social movements based on the participant observation made during the VII March of LGBT Pride in Bahía Blanca in 2017. This unique event allows us to reflect on the social role of the public space through which it runs, the dimensions of the demonstration involved and the imaginaries intersections that the case acquires with its equivalent in the national capital in a mission oriented to federalize these experiences.

Key words: Geography of sexualities; Socioterritorials movements; Non-metropolitans spaces; Interscalarity

\footnotetext{
* Una versión sumamente preliminar ha sido expuesta en el IV Seminario Latinoamericano de Geografía, Género y Sexualidades que tuvo lugar en Tandil entre el 13 y 15 de noviembre de 2019. Cabe destacar que el trabajo se inscribió en el eje temático "Movimientos sociales de base territorial, género y política", siendo éste el más deshabitado del congreso (solo 4 ponencias fueron presentadas).
} grafía, (27), 042. DOI: https://doi.org/10.37838/unicen/est.27-042 


\section{INTRODUCCIÓN}

La renovación temática promovida por los giros culturales de la década de 1990 (Nogué y Romero 2006; Lindón y Hiernaux 2010) ha beneficiado el diálogo de la geografía con el corpus de otras ciencias sociales derivando en una expansión de intereses que acentuaron la crítica de marcos y conceptos instrumentales heredados de la escuela más positivista al tiempo que produjo otros. Los movimientos sociales se constituyen en un nuevo tema de incumbencia de la geografía social (Herin, 2006) con más antecedentes en la dimensión rural (Gonçalves, 2001; Fernándes, 2005; De Castro, 2013) y menos en la urbana. Este despertar es entendido por Oslender (2008) como el giro geográfico de los movimientos sociales que se inserta como parte de la ciudad movimiento (Lindón, 2017) en contraposición a los enfoques morfológicos que han dominado el subcampo. En este sentido, Lindón asume que "la ciudad y la vida urbana resultan mutiladas en su esencia misma cuando son consideradas sólo como formas espaciales" (2017, p. 108).

Por otro lado, los principales registros empíricos acerca de los movimientos sociourbanos en Argentina no han incurrido en el análisis 'emocional' que se corona en las Marchas del Orgullo (objeto de este trabajo) sino que han privilegiado los encuadres materialistas del derecho a la ciudad. Es por ello que el escrito busca exaltar la utilidad de la mirada geográfica aparejada a la Marcha del Orgullo de Bahía Blanca del 2017 en la búsqueda de subrayar la fase territorial desde el espacio percibido (acciones) y el espacio vivido (imaginarios) en términos de Lefebvre (2013).

El escrito se estructura en tres partes. La primera asume la cuestión territorial del movimiento inspirado en el sujeto-sentimiento (Lindón, 2009); en la segunda se repara en los registros del trabajo de campo para culminar, en un tercer apartado, con el tema de los imaginarios comparados (espacios metropolitanos versus espacios no metropolitanos) en torno a la marcha en discusión.

\section{BASES DEL MOVIMIENTO LGBT: TERRITORIO Y SENTIMIENTO}

Delgado Ruiz (2004) explica que la movilización (como categoría genérica) comprende distintos rangos de enunciación como la fiesta y la manifestación, cuyo modus confluye en la idea de 'escenario' (Lindón, 2007) por la fugacidad, excepcionalidad y el sentido de lugar que reportan. En el caso de las manifestaciones los congregados retratan una herida infringida, una derrota injusta, una ofensa crónica como epifanía de un sector de ciudadanos habitualmente invisibilizados o víctimas desconsideradas por su identidad (Delgado Ruiz, 2004, 2017; Offner, 1980). El acto de manifestarse consiste en:

...concentrarse deliberadamente en un lugar público, preferiblemente un lugar que combine la visibilidad con la significación simbólica; mostrar tanto la pertenencia a una población políticamente significativa, como el apoyo a una postura mediante proclamas orales, palabras escritas $u$ objetos simbólicos, y comunicar una cierta determinación colectiva por medio de una actuación disciplinada en un lugar o atravesando una serie de lugares. (Tilly, 2007, pp. 201-202)

De algún modo, las manifestaciones reflejan las prácticas espaciales lefebvrianas ${ }^{1}$ punzando por una apropiación más íntima que lleva a un 'espacio percibido territorializado' donde se encarnan las asimetrías de poder entre la hegemonía (el que domina) y la subalternidad (el que resiste). Si bien cada manifestación puede reproducir una serie de elementos comunes, los llamados movimientos sociales de segunda generación oponen perfiles de resistencia plasmados en insignias eclécticas: feminismos, identificaciones LGBTIQ+, defensores del medio ambiente, reivindicación de los pueblos originarios, entre otros (Iglesias Turrión, 2006; Tilly, 2006).

Jasper (2012a) brinda un aporte microsocial de estas insurrecciones y recalca la importancia

1 Este espacio vincula realidad cotidiana y realidad urbana, englobando tanto la producción como la reproducción social. Los espacios de representación y las representaciones del espacio son los otros componentes de la trialéctica. El primero atañe a los imaginarios y el segundo es el espacio concebido, el de los expertos, los científicos, los planificadores (Lefebvre, 2013 [1974]). 
de considerar otros elementos en su abordaje: estados de ánimo, lealtades afectivas, compromisos morales, negociaciones, identidades en pugna, memorias, sentimientos de eficacia y control, satanizaciones, escalamientos, entre otros. Con este espectro el autor enfatiza el componente emocional, que no remite a la obtención de un beneficio individual o puramente sectorial o de clase sino que está más preocupado por desafiar los esquemas interpretativos dominantes. "Las dimensiones cruciales de la vida diaria (tiempo, espacio, relaciones interpersonales, identidad personal y de grupo) han sido incorporadas en estos conflictos y nuevos actores han reclamado su autonomía para darle sentido a sus vidas" (Jasper, 2012a, p. 22). Bajo este encuadre, el sociólogo propone dos objetivos que resultan interesantes que sirven para analizar el movimiento de las disidencias sexuales en particular. Por un lado la 'reputación', definida como una clase de sentimiento de largo plazo que responde a la forma de cómo vivimos y a las valoraciones de los otros, por lo tanto, oscilante entre el estigma y los estereotipos de normalidad. Ésta es entendida como una 'emoción moral' que tiende a engrosar "los sentimientos de aprobación o rechazo basados en intuiciones o principios morales" (Jasper, 2012b, p. 50). Dicho sentimiento se construye en base a una acumulación de experiencias de aprendizaje que sostienen una impronta marcada por la autonomía y el reconocimiento. Por otro lado, el segundo de los objetivos perseguidos es el 'impacto sobre el mundo', una reacción de corto plazo, una 'emoción refleja' que se gesta y desarrolla en el entorno físico y social inmediato. En el impacto se concreta la versión más transgresora del movimiento, "los activistas deben balancear los placeres de conseguir un impacto con una continua sensación de miedo, ira, y amenaza que demanda la acción constante" (Jasper, 2012b, p. 54). Tanto la reputación como el impacto se calibran dinámicamente en términos de energía negativa o positiva de acuerdo al contexto y esto mide la magnitud del movimiento.

Cabe destacar que no todos los movimientos de origen sociocultural poseen una prerrogativa socioterritorial. Para Fernandes (2005) existe una distinción cardinal entre movimientos socioespaciales y socioterritoriales. Más allá de repasar que los fenómenos sociales poseen un marco espacial, el territorio como elemento político del espacio geográfico no es solo una plataforma de los movimientos en cuestión sino su razón de existencia. Como postula el brasileño, las ONGs son casos de movimientos socioespaciales porque validan representaciones de reivindicación al convocar sujetos mediadores, usualmente voceros del grupo de interés real. En este ejemplo no se 'corporizan' los reclamos y, como consecuencia no ameritan ser considerados socioterritoriales. En El mito de la desterritorialización de Haesbaert (2011) el geógrafo explica los matices de las activaciones territoriales con la figura del peón-golondrina. Cuando este se desenvuelve como trabajador rural no está desterritorializado a pesar de que en ese momento adopta un rol específico, sino que se trata de 'territorialidades latentes'. Ocurre lo mismo con las disidencias sexuales, siendo las experiencias de opresión de la cotidianeidad los puntos de canalización de la territorialidad en el marco de escenarios de disputa. Sack (1986) explica que la territorialidad es la tentativa, por parte de un individuo o grupo, de llegar a afectar, influir o controlar personas, fenómenos y relaciones, mediante la delimitación y afirmación del control sobre un área geográfica. Por lo tanto puede ser activada o desactivada como recurso estratégico de exclusividad (limitación) de acuerdo con la comunidad ${ }^{2}$ en cuestión. En la fase de activación se produce la territorialidad efectiva o la profanación intencional en términos de Bourdieu (2006) que busca expresamente subvertir un orden a partir de un actor político. En cambio, la desactivación es sólo una desterritorialización aparente.

Una especificidad del movimiento de LGBT

2 Yi Fu Tuan (2018) [2002] explica que si bien el concepto de comunidad ha recibido críticas, la función política y las relaciones sostenidas (a pesar de ser conflictivas) que se construyen en ésta no hacen posible su intercambio indistinto por el término grupo. 
es su condición cíclica. Al igual que la toma de calles del colectivo feminista en torno a la fecha-eje del 8 de marzo (Día Internacional de la Mujer), el Día del Orgullo funciona como un recordatorio obligado para salir (Delgado Ruiz, 2017). El mes de junio funciona como un significante global que rememora los disturbios de Stonewall ocurridos el 28 de ese mismo mes en 1969, a partir del cual se reavivan los anhelos del Gay power en las distintas marchas alrededor del mundo que incorporan sus propios condimen$\operatorname{tos}^{3}$. Cocciarini (s/f) hace una crónica de este hecho al que le otorga el carácter de leyenda y explica que no solo inauguró el momento donde la lucha salió a la calle sino la sustanciación de una lucha con cruces generacionales, de clase, de orígenes y de género que posibilitó la formación de una comunidad cohesionada que luego formaría el Frente de Liberación Gay (GLF).

En la actualidad la acción LGBT conforma un "movimiento socioterritorial territorializado" (Fernandes, 2005, p. 32) que actúa en diversos lugares-regiones diagramando una red de relaciones estratégicas que promueven y fomentan su territorialidad. Todos los movimientos territorializados comienzan como movimientos aislados en centros simbólicos como las capitales; estos al territorializarse y romper con la escala metropolitana se organizan en redes, por ejemplo a través de la Federación Argentina de Lesbianas, Gays, Bisexuales y Trans (FALGBT) ampliando sus horizontes políticos y densificando sus alegorías espaciales. En la radiografía argentina (que suele ser homologable a la capital) Moreno (2008) postula que en la década de 1980 fueron movimientos liderados por organizaciones compuestas por gays y lesbianas ${ }^{4}$; en la década de 1990 fueron travestis

\footnotetext{
3 En un intercambio por facebook Esteban Paulón, vicepresidente de la Federación Argentina de Lesbianas, Gays, Bisexuales y Trans (FALGBT) explica que la marcha acaecida durante el mes de junio coincidente con el Día del Orgullo a nivel internacional evoca los disturbios de Stonewall mientras que la del mes de noviembre, considerado el mes de la diversidad, refleja la historia de las organizaciones LGBT argentinas.

4 El historiador argentino Simonetto ha analizado la genealogía del Frente de Liberación Homosexual (FLH) y su relación con otros movimientos en Latinoamérica (2017).
}

y transexuales y hacia finales ésta comienzan a aparecer reivindicaciones en nombre de bisexuales, transgéneros e intersexuales ${ }^{5}$.

Estas apuestas son útiles desde el eje de indagación propuesto por las geografías feministas latinoamericanas: el cuerpo-tierra-territorialidad (Zaragocin Caravajal, Moreano Venegas y Álvarez Velasco, 2018). Si bien este es un aspecto que no se ahondará en el presente artículo, el cuerpo constituye un objeto de estudio geográfico (Silva, Ornat, Cesar, Chimin Jr. y Przybysz, 2013; Johnston y Longhurst, 2010; Lindón, 2009) que permite dar cuenta de agencias y comportamientos a través del continuum de la corporeidad (Pile y Thrift, 1995, McDowell, 2000). Los alcances de la performance como punto de producción y/o reproducción sociosexual también colaboran en la comprensión de lo urbano. En esta dirección, las 'expresiones de género' como coreografías del cuerpo son parte del impacto sobre el mundo en el caso de las disidencias sexuales. Dichas expresiones son entendidas como la manifestación externa de los rasgos culturales que permiten identificar a una persona como masculina o femenina por una determinada sociedad en un momento histórico en base a posturas, formas de vestir, gestos, pautas del lenguaje, comportamiento e interacciones sociales que "pueden alterar las expectativas de género y ser motivo de sanción social" (Comisión Interamericana de Derechos Humanos en De Stéfano Barbero y Boy, 2017, p. 16).

\section{Crónica del orgullo en Bahía Blanca ${ }^{6}$}

El 11 de noviembre a las 16:30 horas se empiezan a concentrar en la Plaza Rivadavia, plaza principal de Bahía Blanca, personas cuyas expresiones

5 Se puede agregar que en la actualidad se ha producido una visibilización de otras disidencias relevantes que se enmarcan en el terreno erótico, como la demisexualidad, la asexualidad además del no binarismo.

6 Bahía Blanca constituye el principal núcleo urbano de la región del sudoeste de la provincia de Buenos Aires, posee poco más de 300.000 habitantes según el último censo poblacional (INDEC, 2010) y conforma un área de múltiples servicios (educativos, financieros, comerciales, sanitarios, deportivos) empleada por las localidades aledañas. Su ubicación geográfica también la posiciona como un importante centro de distribución como puerta hacia el sur o como enlace hacia la capital nacional. 
de género se proponen distar de los apuñados transeúntes de modo enfático. Algunos concurrentes flamean banderas con mensajes disruptivos, portaban pañuelos y pelucas del color del arco iris y otros rasgos de su montaje reposan en sus rostros con glitter (Figura 1). Se muestran contentos, despabilados y cargados de adrenalina, cuestión que los mantiene levantando carteles y tocando bombos en la previa. La escena se inunda de saludos, abrazos, carcajadas y capturas fotográficas entre aquellos que parecen reencontrarse por una causa extra-ordinaria: "hoy es diferente, es especial" me expresa una joven preparada para dar los primeros pasos, cerca de las 17:30 horas.

Figura 1. Momento de previa de la VII Marcha del Orgullo de Bahía Blanca
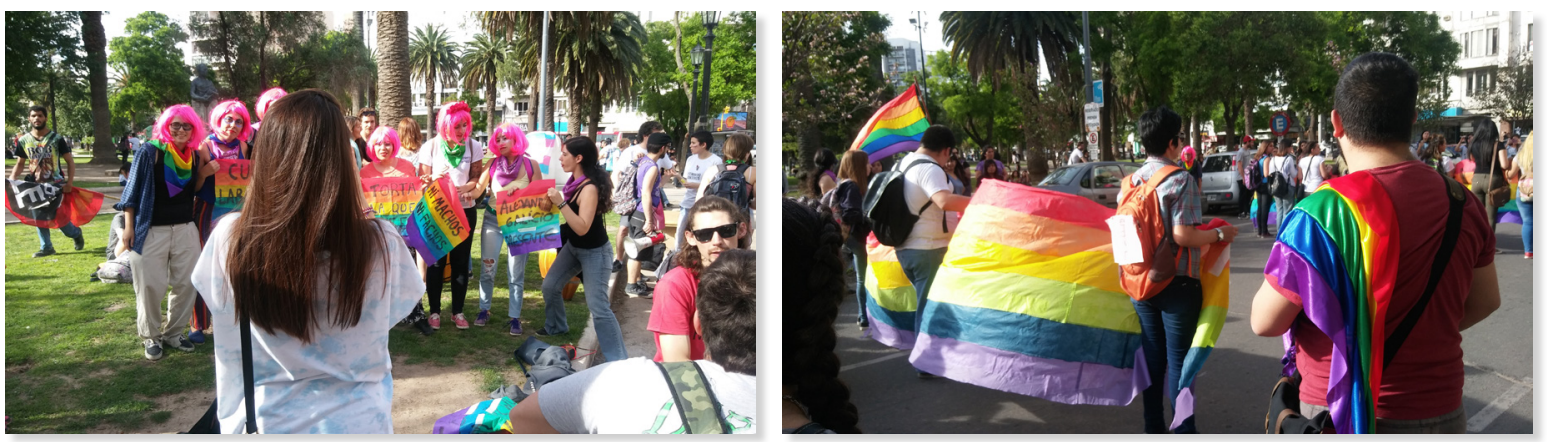

Fuente: archivo del autor (2017)

La marcha convocó a aproximadamente 400 personas según difundieron algunos medios locales días después (La Nueva Provincia y Corriendo la Voz), una cifra interesante si la confrontamos con las representaciones que acusa la localidad" y los "diez gatos locos" que recuerda Cecilia (testimonio de entrevista) en sus albores. La organización y el protocolo están presentes en los lugares que van tomando gradualmente los concurrentes en el armado de la marcha. Como asume Delgado Ruiz:

\section{la distribución de los actores y de los repertorios simbólicos no es nunca arbitraria; la disposición de cada uno de los elementos es el resultado de una tarea discriminatoria de la que la fuente es una determinada organización de las posiciones y morfologías. (1997, p. 40)}

Cabe decir que previamente las consignas fueron discutidas por agrupaciones diversas: Orgullo Disidente, la Juventud LGBT del Partido de los Trabajadores Socialistas y Pan y Rosas, Acciones Feministas, las Socorristas en Red, Bisexuales

7 Orsi (2013) se centra en ciertas características de los bahienses que aparecen en sus entrevistas (en relación a la inmigración): el bahiense es "prejuicioso", "cerrado", "superior", "careta" y "discriminador" pero por sobre todo "indiferente".
Feministas, Autoconvocadas y Resitrans ${ }^{8}$; y las mismas se centraron principalmente en el reclamo por el cupo laboral trans, el cese de los travesticidios, la desarticulación del protocolo que emitió el Ministerio de Seguridad ${ }^{9}$, la separación de la Iglesia del Estado y la no discriminación.

El itinerario de la marcha (Figura 2) parte desde la Municipalidad sobre Alsina, una de las calles que bordean la plaza central de la ciudad y rodea la manzana en un ejercicio de ritual interpelante frente a los edificios patrimoniales dispuestos alrededor (aquí se encuentra el caso histórico de la ciudad) que se asumen hegemónicos: el Palacio Municipal, la Iglesia de Nuestra Señora de la Merced y la antigua sede de la imprenta de La Nueva Provincia, un diario con fuertes vínculos con la última dictadura militar

8 Acompañaron también el Centro de Estudiantes de Humanidades, el sindicato ADUNS, Artistas por la no violencia hacia mujeres, niñas y niños, la Asociación Argentina de Actores, FM de la Calle, el Frente de Feminismo del Colectivo Pueblo en Lucha, Puño y Letra (Comunismo Revolucionario e independientes), Cardumen, MST y Juntas y a la Izquierda.

9 Se trata del Protocolo General de Actuación de Registros Personales y Detención para Personas Pertenecientes al Colectivo LGBTI+ (Res.1149-E) que reincorpora la arbitrariedad en la detención policial, vulnerando principalmente a la población travesti trans. 
(Cernadas y Orbe, 2013). Transcurrir frente al pórtico eclesiástico para las disidencias significa un cortocircuito con el discurso pecaminoso que para la religión todavía ostenta la homosexualidad. En este episodio, lejos de ser una identidad virtual (Goffman, 2006) el pecado está corporizado en una comunidad preparada para saldar deudas históricas. Al grito de "somos la muerte de la moral" los manifestantes ejercen una primera muestra de esa compensación en términos de 'reputación'. Las miradas de quienes se encuentran próximos a ingresar al recinto parecen sorprendidas, tal vez descubren que también son destinatarios de tal mensaje. Al retornar al punto de origen, la marcha emprende un recorrido recto por la calle Alsina hacia otro edificio representativo de la cultura local: el Teatro Municipal. A medida que se avanza continúan las exclamaciones que van ganando fuerza: "alerta al que camina, la lucha disidente en las calles de Bahía" "al calabozo no volvemos más", son algunas vociferaciones que buscan 'impacto' inmediato en la referencia a las condiciones de cercenamiento y clandestinidad a las que han sido condenados muchos de sus pares en el pasado reciente. Como se trata de una semipeatonal con locales de ropa y gastronómicos, algunos comerciantes salen y vuelven rápido a su trabajo, la mayoría siguen la marcha tras la vidriera que funciona como un polarizado y otros transeúntes escrutan con expresión rígida el 'escenario' montado. Resulta evidente la disconformidad en el lenguaje corporal de la audiencia. En este tramo de la procesión se suman actos homoeróticos a modo de emociones reflejas combativas frente al monitoreo de sus espectadores. Durante los cortos minutos que los autoconvocados territorializaron el teatro, las personas presentes en el sector de ingreso y en la plazoleta aledaña se muestran incómodas lanzando miradas de desaprobación, posiblemente porque también había niños pequeños. En este momento algunas cámaras de medios locales aparecen y se toman testimonios ${ }^{10}$; la efervescencia se acerca

10 En su estudio Settanni (2013) revela que en estas marchas la calle se convierte en un verdadero puesto de control fronte- a un punto de ebullición ya que, a pocos metros, espera un fragmento especial para los bahienses: la avenida Alem.

La marcha toma solo un carril de dicha avenida, una de las arterias de mayor dinamismo en la actualidad donde predomina la función comercial (numerosos restaurantes, cervecerías, heladerías y confiterías) intercalada con la residencial. Marchar por esta senda es inusual dado que no prosigue el tradicional recorrido circular de otras marchas en torno a la plaza a modo de cúmulo centrípeto (Delgado Ruiz, 1997) sino que prolifera más allá de dicho reducto (en donde se agotaban marchas anteriores) penetrando hacia otros ribetes del espacio que amplían la semiosfera comunicativa pero también desafían los sentidos sedimentados. Si en el tramo anterior la tensión iba en aumento, atravesar la "Palermo bahiense"11 conduce a que la disputa espacial esté declarada. La calle, al ser un espacio de uso común, constituye una de las pocas oportunidades de careo entre la hegemonía y la subalternidad y, como afirma Enguix (2009) la visibilidad deviene clave en un contexto de interacción entre grupos desiguales.

La burbuja espacial de la avenida Alem se pone en tensión desde el primer minuto; parte de quienes meriendan en las afueras de los locales optan por recluirse adentro o directamente ignorar la etnografía sonora (Martín y Fernández Trejo, 2017). Por otro lado, desde algunos balcones se lanzan reacciones como "vayan a laburar" o "déjense de joder con las marchas", y en algunas intersecciones un par de conductores intentan adelantarse y fragmentar la marcha sin éxito por el control del personal policial designado para encauzar la movilización. Asimismo, algunas personas en los balcones parecen pendientes pero inexpresivas como demostrando cierta condición de 'dueños' de la Avenida ${ }^{12}$ en

rizo, y los periodistas allí apostados ejercen el rol de agentes de aduana que deciden a quién es necesario revisar y someter, y la manera de hacerlo.

11 Así la cataloga el diario local La Nueva Provincia en la edición de fascículos coleccionables dedicados a los barrios bahienses (2004).

12 Resulta interesante preguntarse por qué avenida suele plas- 
tanto propietarios de sus inmuebles solo controlan a sus 'huéspedes'. Esta atmósfera de segregación simbólica se aborta por uno de los chicos de PTS que emplea el megáfono: "señor, señora, no sea indiferente, se matan a las travas en la cara de la gente". La carga del mensaje no es casual al discurrir por este territorio. Los travesticidios renuevan el vigor de las demandas y funcionan como un 'shock moral', definido como un mecanismo para inducir retóricas empáticas (Jasper, $2012 b$ ) ya que personas que pasan por allí se ven interpeladas por el enunciado y se suman a la movilización. Como consecuencia, el interés del impacto no se limita a un embate contra sectores que discrepan con las consignas evocadas sino que rastrea, en la creatividad del reclamo cantado, a aquellos que sienten afinidad con lo que resuena pero que muchas veces piensan que es mejor no meterse ("bahiense no sea indiferente").

La movilización emprende su curso final cuando se desvía por calle Casanova hacia la zona conocida como "el parador" atravesando el espacio verde más frecuentado y valorado de la ciudad: el Paseo de las Esculturas ${ }^{13}$. La marcha se ensancha, desborda e interrumpe el paisaje de los jóvenes tendidos sobre el césped, quienes toman mates. No se aprecia en los receptores ni la reacción sorpresiva ocurrida frente a la Iglesia, ni la mirada curiosa que gobernó la calle Alsina y tampoco la rigidez de los usuarios que estaban en la avenida Alem. Sin embargo, en este punto se constata que las identificaciones sexuales no son siempre pensadas como disidencias para personas gays o lesbianas. Durante la transición por allí un varón gay que estaba marchando le comenta a su amiga que había visto a "tipos" con los que "había estado" y que estos habían esquivado su mirada al verlo

marse en mayúscula y calle es una palabra condenada a la minúscula. Dicho caso busca enfatizar que, de algún modo, esas interpretaciones semánticas son disputas espaciales simbólicas en términos de usuarios y funciones.

13 El paseo se encuentra emplazado en la Avenida Urquiza, sobre el entubado del Arroyo Napostá, y está ornamentado con obras llevadas a cabo durante el $1^{\circ}$ Simposio Nacional de Escultura Monumental realizado en la ciudad. Aquí se concentran muchas familias y estudiantes (dada su cercanía a la Universidad), principalmente durante los fines de semana. inmerso en el 'ritual'. Se puede establecer que lo que se piensa como reputación puede ser paradojal de acuerdo quién sea su intérprete y este es uno de los factores que agrieta la comunidad en cuestión ya que escinde a los 'orgullosos' de los 'reservados' ${ }^{14}$ como prefieren nominarse los que no se involucran en "esas cosas" (entrevista con Juan, 27 años). Cabe destacar que las principales portavoces (que sostenían el megáfono y lideraban) de la marcha pivotean entre personas trans y gays, pero el cúmulo que concretamente la edificaba estaba compuesto por chicas (no se puede asumir que todas ellas eran lesbianas porque no lo sabemos), quienes también fueron las que causaron impacto momentos atrás a partir de las prácticas de escrache y chapadas (losa y Rabbia, 2010). Mediante la invocación "tengo todo lo que te incomoda", la acción colectiva cuestiona no sólo la heteronormatividad sino a su hermana menor: la homonormatividad arribando a una división ideológica que pone en entredicho las políticas asimilacionistas en detrimento de los compromisos políticos de corte radical (losa y Rabbia, 2010) que han sido constantes bifurcaciones en el movimiento LGBT ${ }^{15}$.

La dimensión de la fiesta acaece en el destino final anidado en un rincón del paseo próximo al Puente Amarillo; allí se produce la distensión luego de la labor reivindicativa más encarnizada. La venta de fanzines LGBT, la música a cargo del grupo Las Desbandadas y la lectura de documentos y poemas por parte de algunos referentes intelectuales LGBT locales, amalgaman lo artístico de la protesta mientras el resto reposa sobre la hierba. Asimismo, este fue un momento de mixtura con otros transeúntes que

14 Esta referencia ha sido reportada también en otras investigaciones específicamente en el uso de aplicaciones de citas (Larreche, 2018). Aquellos perfiles que se presentan como reservados poseen determinadas conductas que se perciben como dominantes en estos los espacios virtuales no metropolitanos tales como no pasar foto de cara y asociar lo reservado con lo masculino. En los procesos colectivos que estamos analizando "no pasar foto de cara" se traduce en "no poner la cara" y esto es, en definitiva, "no poner el cuerpo" de una forma política. Es el cuerpo mercantil en estas apps lo que funciona como un imperativo.

15 Véase Vélez Pelligrini (2008). 
pasan por allí y que, en algunas ocasiones, eligen pararse a observar. Para Delgado Ruiz

se trata de fusiones, pero no fusiones estabilizadas y claramente delimitadas, a la manera como se supone que pasa con las comunidades tradicionales, sino fusiones que se organizan a partir de una coincidencia provisional que puede ser afectiva, psicológica, ideológica o de cualquier otro tipo, pero que no dura más allá del momento preciso en que se produce y sólo mientras se produce. (Delgado Ruiz, 2004, p. 126)

\section{La fiesta entonces:}

no sólo visibiliza una microsociedad, sino el sistema de negociaciones que hace posible la articulación entre los segmentos que la conforman, determinando por pocos minutos una conversión del mero paisaje urbano en un paisaje moral: la condensación festiva que se corona con la música y el baile establece entonces una malla sobre el espacio público, sobre la cual se representan las solidaridades y los encontronazos entre quiénes siendo incompatibles se necesitan. (Delgado Ruiz, 1997, p. 39)

Como postula el antropólogo español si "toda fiesta emite un jsomos!, la manifestación añade otras fórmulas más específicas y personales como: ' $i . . . y$ queremos!, $; \ldots$ y decimos, $; \ldots . . y$ exigimos, i...y denunciamos!'” (Delgado Ruiz, 2004, p. 7) (cursivas en el original)

Figura 2. Recorrido VII Marcha de Orgullo de Bahía Blanca

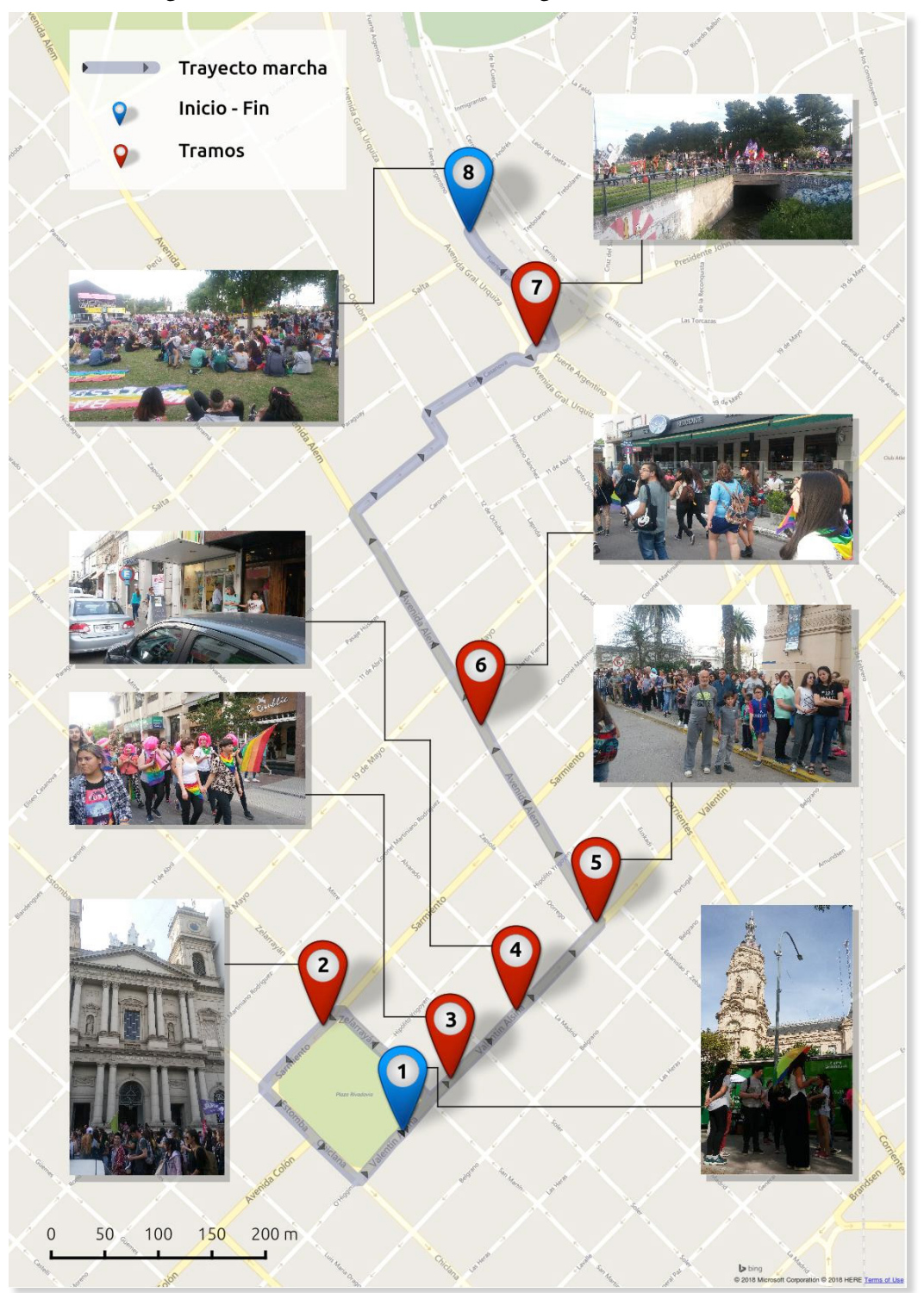

Fuente: elaboración personal (2017) 


\section{A MARCHAS DISTANTES, IMAGINARIOS CONVERGENTES}

Los movimientos sociales deben entenderse en conjunción con las redes culturales sumergidas en la vida cotidiana de las que emergen (Melucci, 1989). Son de público conocimiento las institucionalizaciones oblicuas (Figari, 2010) a nivel nacional que se sucedieron ante la conquista de ciudadanías sexuales (leyes de Matrimonio Igualitario e Identidad de género) y la falta de consensos sobre las vivencias LGBT que se irrigaron la vasta geografía nacional. El letargo de la acción colectiva en espacios no metropolitanos puede demostrar que muchas veces la geografía cultural precede a la geografía política (Di Meo y Buléon, 2005).

Alojadas en las metrópolis, las marchas LGBT o LGBTIQ+ están parafraseadas por los medios de comunicación principalmente por el sentido de lo carnavalesco; se trata de un evento de ímpetu turístico más que político ${ }^{16}$. Entre los testimonios recogidos, algunos disidentes bahienses destacan el show que se vive en Buenos Aires el día de la marcha. Augusto, uno de los miembros de Orgullo Disidente, remarca que este era el motivo principal por el cual "las marchas no se solapan en un mismo día" señalando que muchos gays viajan a la capital para participar de la misma y lamentando que no sea recíproca tal demostración en su ciudad natal. Asimismo, este deseo parece más frecuente entre gays que entre lesbianas ya que "se sabe que es un lugar de levante". Sin embargo, este imaginario que es positivo para los 'no porteños' resulta un nudo problemático para los organizadores de la marcha capitalina.

El peligro de extinción del clamor disidente es un punto de discusión neurálgico en los últimos años, tal es así que se han catapultado contramarchas minoritarias en paralelo para no prescindir de las voces transgresoras en el marco de la celebración (Moreno, 2008; losa y Rabbia, 2010). Si bien es distintiva la naturaleza

16 Villena (2019) en una nota para diario español El País analiza las intenciones del Grupo Parlamentario de Ciudadanos en la Asamblea de Madrid de declarar la marcha del orgullo como fiesta de interés turístico regional. Consultar https://elpais. com/ccaa/2019/02/07/madrid/1549554339_982271.html estético-política, el estudio de Moreno no parece compartir la figura de un 'mercado militante' como sostienen Figari y Rapisardi (2005) cuando enarbolan una especie de oxímoron explicativo de la marcha en $\mathrm{CABA}^{17}$. Si bien los dos planos mercado-militancia, protesta-fiesta están presentes, esclarecer que en la puja de tales versiones el peso ha recaído sobre la versión light del orgullo (y no sobre la fundante) no es menor. En esta dirección, se debe guardar cautela frente a la visión ecuánime de Sívori:

las marchas LGBT actuales son a la vez protesta y celebración. Protesta contra la violencia sexista, la homofobia y la discriminación que persisten en la calle, en la escuela, en el trabajo, en el hogar. Celebración de la imaginación y perseverancia de quienes enfrentan esa violencia día a día, y aun así viven su sexualidad con alegría. (Cocciarini, s/f, p. 3)

El "aun así" de la cita alumbra la persistencia de opresión ${ }^{18}$ que Moreno (2008) busca subrayar en su sentido de contramarcha. De hecho la convivencia de estas dos células se extendió por poco tiempo cuando los desacuerdos fueron irreconciliables en el debate sobre la prostitución trans y provocaron la realización de dos marchas con recorridos disímiles en el año 2018, convocadas para el 10 y el 17 de noviembre respectivamente. Esta última se dirigió a enaltecer los valores de orgullo y lucha perdidos según testimonian organizaciones:

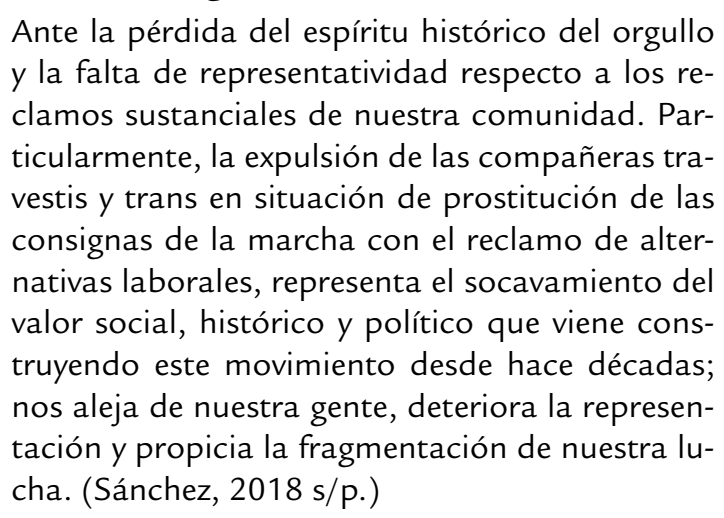

En Bahía Blanca el nivel de las discusiones y,

17 Ciudad Autónoma de Buenos Aires

18 "El fenómeno de la opresión tiene dos dimensiones analíticas vinculadas con la identificación de los procesos que originan las desventajas estructurales: injusticias causadas por procesos económicos e injusticias basadas en procesos culturales" (Moreno 2008, p. 226). 
en particular, la injerencia del Estado o del sector empresarial en este movimiento son inexistentes con respecto a CABA donde, por ejemplo, el oficialismo buscó contener la marcha del 2018 por la visita del FMI, recortándola en Palermo. Por otro lado, en otro espacio metropolitano como Córdoba, analizada por losa y Rabbia (2010), el ingreso de las firmas de los boliches en el evento alumbra el instrumentalismo del capitalismo rosa.

La marcha del orgullo bahiense es joven (en CABA se celebra desde el año 1992 mientras que se repasó la edición VII en Bahía Blanca) y, por lo tanto, requiere un sentido de comunión estratégica como primer paso. Por otro lado, en lo relativo al radio de influencia de la movilización todavía no interfiere en la dinámica de la ciudad como sí ocurre en las metrópolis donde se torna masiva y permanente; en Bahía Blanca solo dura un par de horas (escenario) mientras que en CABA ocupa gran parte del día. En tercer lugar, esta marcha no suscita interés sectorial público o privado que emule apoyos sinceros o adscripciones forzadas como eco de lo políticamente correcto como sí ocurre en los espacios metropolitanos. La indiferencia es otro contrapunto. Esta es más ostensible en el anonimato de aglomeraciones millonarias que desentona en los círculos sociales de distribución conocida que se reportan en Bahía Blanca y, en tal sentido, la 'política de visibilidad' (Bellucci y Rapisardi, 1990) es también una decisión con consecuencias palpables en lo inmediato: "si voy... sería un quemo" comenta Manuel en una conversación informal. Si a ello le sumamos la posibilidad de que el evento sea cubierto $y$ transmitido por medios locales (como ocurrió en la marcha relatada), la individualización se agudiza de forma dramática. Como dictamina Simmel (2014), el padre de las fronteras sociales, cuanto más identificable sea un colectivo menos posibilidades de diferenciación biográfica tendrán sus integrantes. Al no existir garantías de anonimato la marcha despierta gran ansiedad sobre sus protagonistas efectivos $y$ también sobre los potenciales. Ciertamente, en
CABA la territorialidad de la marcha pasa a ser un fenómeno menos acusador también porque en las escenas cotidianas de la ciudad se presencian frecuentemente besos o caminatas de la mano en plazas, shoppings, subtes $y$, asimismo, los transeúntes pueden reconocer determinado circuito de ocio LGBT privado como cines, saunas o bares en áreas céntricas. Para los bahienses los efectos fugaces pero territoriales de marchar funciona como la 'punta del iceberg' ya que luego de la euforia, las prácticas, deseos y decisiones en las trayectorias diarias siguen en evaluación, afectando a aquel que posee registros espaciales generalmente heteronormativos (laborales, educativos, familiares) en donde las credenciales neutrales son mejor bienvenidas.

Por último, en CABA también se aprecia la multiplicidad de estrategias de presentación (Enguix, 2009) como osos, leather, drags, sugardaddys y demás "tribus" 19 que no tienen su correlato en espacios no metropolitanos como el caso analizado ${ }^{20}$; así como tampoco la presencia de asociaciones de profesionales, ligas deportivas o familias de jóvenes LGBT. La mayoría de quienes tomaron las calles compartía un rango etario y estaban vinculados por centros estudiantiles sin rastros del entorno familiar o de figuras políticas. Si bien entre una movilización y la otra se evidencian los factores esbozados por Tilly (1995) como magnitud y determinación, los 'imaginarios geográficos' también son un elemento a tener en cuenta. Lindón (2008) los define como tramas subjetivas que derivan de otros hechos, objetos, sujetos y conjuntos de prácticas que se desarrollan en otros lugares, es decir, proceden de cotidianeidades distantes pero articuladas. Estos son actantes en la medida que "pueden no representar ningún fenómeno local y, paradójicamente, modelar las prácticas coti-

19 Así es la referencia empleada por la aplicación conocida como Grindr (destinada a hombres gays y bisexuales) para compartimentar en categorías sus realidades corporales en virtud de ajustar el interés ante sus receptores.

20 Bernieri Ponce (2019) es otro de los pocos geógrafos argentinos que ha indagado las Marchas del Orgullo descentradas de la metrópoli con los casos de la ciudad de San Juan, El Bolsón y San Salvador de Jujuy. 
dianas de los sujetos locales" (Lindón, 2017, p. 114) lo que pone de relieve el carácter interescalar de los acontecimientos. Los sucesos políticos, mediáticos, culturales acarreados en torno a la fórmula deseable del matrimonio igualitario (Vespucci, 2017) desde Buenos Aires confirieron un sentido territorial sin precedentes en la disputa LGBT en las calles de Bahía Blanca. Conforme fue avanzando el debate en torno a las ciudadanías basadas en un sujeto-sentimiento, el eco de estas cuestiones en Bahía Blanca no se hizo esperar e inicio su trama. En este sentido, hubo un efecto contagio que se lanzó hacia el cambio social y la creación de resistencia (Lindón, 2017) materializado en la primera marcha del orgullo celebrada en ese mismo año (2010). Con esto se quiere decir que esta tipología de marchas también deben analizarse teniendo en cuenta los procesos diferenciales en las agencias de la comunidad que tienden un puente entre una territorialidad activada y otra que está despertando.

\section{A MODO DE CIERRE}

Los nuevos movimientos sociales como el liderado por las disidencias sexuales expone el potencial analítico de la geografía. Al tratarse de tónicas envueltas en una cultura determinada, estas movilizaciones exaltan un componente emocional encauzado en demandas de garantías vivenciales en detrimento de respuestas materiales. Esta dimensión pone el acento en la escala del sujeto como parte de las exigencias que los torna rituales de tipo socioterritorial y no solo socioespaciales.

En Bahía Blanca estas retóricas de impacto siguen un transcurso cósmico (Delgado Ruiz, 1997) en un sentido zigzagueante que anuda edificios de la historia local que actúan como personajes-fuerza (Meccia, 2016) en tanto portadores de sentidos hegemónicos, y segmentos que se preconciben para un público y no como espacios verdaderamente públicos en términos de coexistencias. En consecuencia, la juventud del orgullo bahiense en conjunción con el statu quo sociosexual del espacio percibido enfatiza la manifestación y la protesta dejando un pequeño lugar a la fiesta como parte del funcionamiento de la batería moral (Jasper, 2012b) propia de estos coros rebeldes (Iglesias Turrión, 2006). La reapropiación del entorno habitual por dos horas al año es la epifanía de apuestas territoriales arriesgadas en el continuum de las reglas sociales generales. La visibilidad se convierte en objeto de gestión diferencial (losa y Rabbia, 2010) de acuerdo principalmente al anonimato que les confiera la demografía y el ethos del espacio. El corte festivo y el dominio consumista criticado en los desfiles de orgullo de los espacios metropolitanos invitan a participar desde un plano apolítico o de intereses difusos. En cambio, en espacios no metropolitanos este tipo de 'escenarios' crean marcas comunales y por ser excepcionales son monitoreados.

Estos imaginarios geográficos enlazan a CABA con Bahía Blanca desde sus diferencias en virtud de romper con la idea de 'una' marcha del orguIlo. Las injusticias cotidianas, tomadas como una desterritorialización simbólica, impulsan los ánimos de organización y configuración de lealtades que se producen en la territorialidad de la marcha y que, ex post, sirven para congeniar propuestas sucesivas a largo plazo. La principal huella de la interescalaridad $y$, tal vez la decisiva, haya sido que el efecto de la implementación de las leyes de Matrimonio Igualitario y de Identidad de Género no repercutió en predisposiciones de aceptación rápidas; aquellos espacios que venían adoptando una perspectiva de diversidad sexual, le dieron continuidad y los que no, las asimilaron con resistencia. Sin embargo, sí funcionaron como 'acontecimientos solidarios' en términos miltonianos ya que "su vinculación procede del movimiento de una totalidad superior a la del lugar en el que se instalan" (Santos, 2000, p. 128). En este sentido, podemos entender la escala también como un tiempo en tanto el acontecimiento está dotado de una extensión cuyo efecto no se produce de forma instantánea pero eso no quita las posibilidades de incidencia en otro lugar.

Desde la mirada de quienes fueron protagonistas en el reclamo de estas ciudadanías sexuales se puede discutir si la ansiada y de- 
batida conquista no inauguró, por un lado, un estadio de somnolencia de las prerrogativas LGBT en los principales centros metropolitanos y, por el otro, despertó el largo letargo del movimiento en espacios no metropolita-

\section{AgradeCIMIENTOS}

A la Dra. Patricia Ercolani (UNS), Dra. Graciela Hernández (UNS-CONICET) y Dra. Laura Torres (UNCuyo-CONICET) por los comentarios

\section{REFERENCIAS}

Bellucci, M. y Rapisardi, F. (1999). Alrededor de la identidad. Luchas políticas del presente. $R e$ vista Nueva Sociedad, (162), 40-53.

Bernieri Ponce, E. (2019). Una mirada geográfica a las Marchas del Orgullo LGBTIQ+ en tres ciudades argentinas a partir de los conceptos de espacio, lugar, territorio y paisaje (pp. 7988). En D. Lan (Comp.) Actas IV Seminario Latinoamericano de Geografía, Género y Sexualidades. Tandil: Universidad Nacional del Centro de la Provincia de Buenos Aires.

Bourdieu, P. (2006). Génesis y estructura del campo religioso. Revista Relaciones, 108.

Cernadas, M. y Orbe, P. (2013). Itinerarios de la prensa: cultura política y representaciones en Bahía Blanca durante el siglo XX. Bahía Blanca: Ediuns.

Cocciarini, N. (s/f). "28 de Junio de 1969: Disturbios De Stonewall”. Uni(+di)versidad. Publicación del programa universitario de diversidad sexual. Rosario: Universidad Nacional del Rosario. Recuperado de http://www.puds.unr.edu.ar/ wpcontent/uploads/2014/07/UNIDIV-Stonewall_Inn.pdf(consulta 15 de mayo de 2018).

De Castro, C.A. (2013). Movimento social e Geografia: contribuição ao debate. Revista Nera, 16(23).

De Stéfano, M. y Boy, M. (2017). Salud y Adolescencias LGTBI. Herramientas de abordaje integral para equipos de salud. Buenos Aires: Ministerio de Salud de la Presidencia de la Nación.

Delgado Ruiz, M. (1997). Ciudad líquida, ciudad interrumpida. Universidad Nacional de Colombia: Biblioteca Pública Piloto de Medellín. nos. Finalmente, el estudio buscó descentrar la mirada de los movimientos disidentes hacia la 'periferia' pero sabiendo que su centro semiótico (la capital) se vuelve una contingencia inevitable en pos de un análisis serio.

brindados en las distintas instancias del proceso de elaboración y al Dr. Nicolás Caruso por sus recomendaciones en materia cartográfica.

Delgado Ruiz, M. (2004). Del movimiento a la movilización. Espacio, ritual y conflicto en contextos urbanos. Maguaré, 18.

Delgado Ruiz, M. (2017). Tomar las calles: la manifestación como ritual político. En J. Padules y J. Uribe (Eds.) La danza de los nadie. Pasos hacia una antropología de las manifestaciones. Barcelona: Pol.len.

Di Meo, G. y Buleon, P. (2005). L'Espace social: une lecture geographique des sociétés. París: ArmandColin.

Enguix, B. (2009). Espacios y disidencias: el orgullo LGTB. Quaderns-e de l'Institut Català d'Antropologia, 14.

Fernandes, B.M. (2005). Movimentos socioterritoriais e movimentos socioespaciais: contribuição teórica para uma leitura geográfica dos movimentos sociais. Revista Nera, 8(6).

Figari, C. (2010). El movimiento LGBT en América Latina: institucionalizaciones oblicuas. En A. Massetti, E. Villanueva y M. Gómez (Comps.) Movilizaciones, protestas e identidades colectivas en la Argentina del bicentenario. Buenos Aires: Nueva Trilce.

Goffman, E. (2006) [1963]. Estigma: la identidad deteriorada. Buenos Aires: Amorrortu.

Gonçalves, C.W. (2001). Geo-grafias: movimientos sociales, nuevas territorialidades y sustentabilidad. México: Siglo Veintiuno.

Haesbaert, R. (2011). El mito de la desterritorialización: del "fin de los territorios" a la multiterritorialidad. México: Siglo Veintiuno.

Herin, R. (2006). Por una geografía social, críti- 
ca y comprometida. Scripta Nova: revista electrónica de geografía y ciencias sociales, (10).

Iglesias Turrión, P. (2006). Un nuevo poder en las calles. Repertorios de acción colectiva del Movimiento global en Europa. De Seattle a Madrid Un nuevo poder en las calles. Política y Sociedad, 42(2), 63-93.

Instituto Nacional de Estadísticas y Censos (INDEC) (2010). Censo Nacional de Población, Hogares y Vivienda. Buenos Aires.

losa, T. y Rabbia, H. (2010). Definiciones divergentes de la estrategia de visibilidad en el movimiento LGTB cordobés. ĺconos, Revista de Ciencias Sociales, 39.

Jasper, J.M. (2012a). ¿De la estructura a la acción? La teoría de los movimientos sociales después de los grandes paradigmas. Sociológica, 27(75), 7-48.

Jasper, J.M. (2012b). Las emociones y los movimientos sociales: veinte años de teoría e investigación. Revista latinoamericana de estudios sobre cuerpos, emociones y sociedad, 3(10), 48-68.

Johnston, L. y Longhurst, R. (2010). Space, place and sex: geographies of sexualities. Rowman \& Littlefield: Lanham.

Larreche, J.I. (2018). Las sexualidades y su capital espacial. Exploraciones teórico-situadas en la ciudad intermedia de Bahía Blanca, Argentina. Cuaderno Urbano, 25(25), 163-183.

Lefebvre, H. (2013) [1974]. La producción del espacio. Madrid: Capitán Swing.

Lindón, A. (2007). Los imaginarios urbanos y el constructivismo geográfico: los hologramas espaciales. Eure, 33(99), 31-46.

Lindón, A. (2008). De las geografías constructivistas a las narrativas de vida espaciales como metodologías geográficas cualitativas. Revista da ANPEGE, 4(04), 7-26.

Lindón, A. (2009). La construcción socioespacial de la ciudad: el sujeto cuerpo y el sujeto sentimiento. Revista Latinoamericana de Estudios sobre cuerpos, emociones y sociedad, (1), 6-20.

Lindón, A. y Hiernaux, D. (2010). Los giros de la geografía humana. Desafíos y horizontes. México: Anthropos.
Lindón, A. (2017). La ciudad movimiento: cotidianidades, afectividades corporizadas y redestopológicas. InMediaciones de la comunicaicón, 12(1), 107-126.

Martin, J.L. y Fernández Trejo, S. (2017). La dimensión acústica de la protesta social: apuntes desde una etnografía sonora. Íconos. Revista de Ciencias Sociales, (59), 103-122

McDowell, L. (2000). Género, identidad y lugar: un estudio de las geografías feministas. Madrid: Ediciones Cátedra.

Meccia, E. (2016). El tiempo no para: Los últimos homosexuales cuentan la historia. Santa Fe: Ediciones UNL.

Melucci, A. (1989). Nomads of the present: social movements and individual needs in contemporary society. Londres: Hutchinson Radius.

Moreno, A. (2008). La invisibilidad como injusticia: Estrategias del movimiento de la diversidad sexual (pp. 217-244). En M. Pecheny, C. Figari y D. Jones (Comps.) Todo sexo es político: Estudio sobre sexualidades en Argentina. Buenos Aires: Libros del Zorzal.

Nogué, J. y Romero, J. (2006). Las otras geografías. Valencia: Tirant lo blanch.

Offner, J.M. (1980). Enjeux politiques et sociales de la marche a pied. Métropolis, 75.

Orsi, L. (2013). Inmigración, identidades y valoraciones en Bahía Blanca. En G. Hernández (Comp.) Lo dicho y los hechos: Investigación y debates de historia oral y etnografía en Bahía Blanca y la región del suroeste bonaerense. Bahía Blanca: Libros en Colectivo.

Oslender, U. (2008). Comunidades negras y espacio en el Pacífico colombiano: hacia un giro geográfico en el estudio de los movimientos sociales. Bogotá: ICANH.

Pile, S. y Thrift, N. (1995). Mapping the subject: geographies of cultural transformation. Psychology Press.

Sack, R. (1986). Human Territoriality: its theory and history. Cambridge: Cambridge University Press.

Santos, M. (2000) [1996]. La naturaleza del espacio. Técnica y tiempo. Razón y emoción. Barcelona: 
Ariel.

Settanni, S. (2013). Las Marchas del Orgullo LGBT y las paradojas de la visibilidad mediática. Trampas de la Comunicación y la Cultura. Tram [p]as de la comunicación y la cultura, (76).

Silva, J.M., Ornat, M., Cesar, T., Chimin Jr., A.B., y Przybysz, J. (2013). O corpo como elemento das geografias feministas e queer: um desafio para a análise no Brasil (pp. 85-142). En J.M. Silva, M. Ornat y A.B. Chimin Jr. (Coords.) Geografías Malditas: Cuerpos sexualidades y espacios. Ponta Grossa: Todapalavra.

Simmel, G. (2014). Sociología. Estudios sobre las formas de socialización. México, D.F.: Fondo de Cultura Económica.

Simonetto, P. (2017). Movimientos de liberación homosexual en América Latina. Aportes historiográficos desde una perspectiva comparada entre Argentina, Brasil, Chile, Colombia y México (1967-1982). Iberoamericana, 17(65), 157-177.

Tilly, C. (1995). Los movimientos sociales como agrupaciones históricamente específicas de actuaciones políticas. Sociológica, 10(28), 13-36.

Tilly, C. (2006). Los movimientos sociales entran en el siglo veintiuno. Política y sociedad, 42(2), 11-35.

Tilly, C. (2007). Pourquoi se mobilise-t'on? Les théories de l'action collective. París: La Décourte-Mauss.

Tuan, Y.F. (2018) [2002]. Comunidad, sociedad e individuo (pp. 170-190). En J. Nogué (Ed.) Yi-Fu Tuan. El arte de la geografía. Barce-
Iona: Icaria.

Vélez Pelligrini, L. (2008). Minorías sexuales y sociología de la diferencia. Gays, lesbianas y transexuales ante el debate identitario. Barcelona: Montesinos.

Vespucci, G. (2017). Homosexualidad, familia y reivindicaciones: De la liberación sexual al matrimonio igualitario. Universidad Nacional de General San Martín: UNSAM Edita.

Zaragocin Carvajal, S.; Moreano Venegas, M. y Álvarez Velasco, S. (2018). Hacia una reapropiación de la geografía crítica en América Latina. Íconos. Revista de Ciencias Sociales, (61), 11-32.

\section{OTRAS FUENTES}

Figari, C. y Rapisardi, F. (2005). La fiesta y la protesta. Suplemento Soy, Página 12. Recuperado de https://www.pagina12.com.ar/diario/ sociedad/subnotas/59455-19681-2005-11-20. html(consulta 2 de febrero de 2019).

Sánchez, N. (2018). Marcha del Orgullo gay: invierten el recorrido y varias agrupaciones se retiraron de la organización. Sección Ciudades, Clarín. Recuperado de https://www.clarin.com/ciudades/ invierten-recorrido-marcha-orgullo-gay-varias-agrupaciones-retiraron-organizacion_0_ YiUolV6Zl.html (consulta 2 de febrero de 2019).

Villena, M. (2019). Ciudadanos propone declarar el Orgullo fiesta de interés turístico. El País. Recuperado de https://elpais.com/ccaa/2019/02/07/ madrid/1549554339_982271.html (consulta 2 de febrero de 2019).

José Ignacio Larreche es Doctorando en Geografía. Becario doctoral del Consejo Nacional de Investigaciones Científicas y Técnicas (CONICET). Es miembro de la Red de Estudios de Geografía, Género y Sexualidad Ibero Latinoamericano (REGGSILA). Docente del Departamento de Geografía y Turismo de la Universidad Nacional del Sur. Sus estudios recientes versan sobre la geografía de las sexualidades en la ciudad de Bahía Blanca y sus intereses generales se orientan hacia las nuevas líneas de la Geografía Cultural con énfasis en el espacio urbano. Departamento de Geografía y Turismo (UNS-CONICET). 12 de octubre 1198, $4^{\circ}$ piso, (8000) Bahía Blanca, Buenos Aires, Argentina. joseilarreche@gmail.com 